\title{
Aproximación a la tradición alegórica en la independencia del Estado de Cartagena, 1805-1814
}

\author{
Approach to the allegorical tradition \\ in the Independence of the State of Cartagena, 1805-1814 \\ Da pena de galeras a fortificações. \\ Uso de prisioneiros em cenários de guerra no império español
}

Albertina Cavadía Torres 1 iD

Universidad Nacional de San Martín, Argentina

Para citaciones: Cavadía, A. (2020).

Aproximación a la tradición alegórica en la independencia del Estado de Cartagena, 1805-1814. El taller de la Historia, $12(2), 358-371$.

Recibido: Mayo de 2020

Aprobado: Octubre de 2020

Autor de correspondencia:

Albertina Cavadía Torres

albertinacavadia@gmail.com

Editor: Sergio Paolo Solano. Universidad de Cartagena-Colombia.

Tipología IBN Publindex: Artículo de Investigación

Copyright: () 2020. Cavadía, A. Este es un artículo de acceso abierto, distribuido bajo los términos de la licencia https://creativecommons.org/licenses/by-

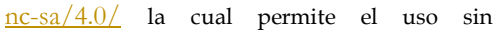
restricciones, distribución y reproducción en cualquier medio, siempre y cuando que el original, el autor y la fuente sean acreditados.

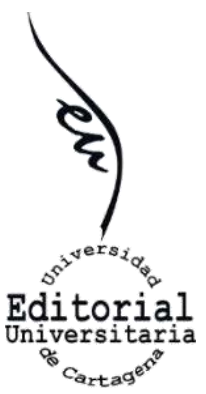

\section{RESUMEN}

Los habitantes de las colonias españolas en el proceso de emancipación y conformación de las primeras repúblicas rediseñaron constantemente la alegoría de América tanto en su representación iconográfica como en su concepto. Por lo cual, este texto se propone estudiar el empleo de esta por parte de la Junta Patriótica para organizar, representar y legitimar un sistema administrativo independiente en la Provincia de Cartagena entre 1805 y 1814. En el primer aparte, se explora el uso de elementos iconográficos como parte del aparato simbólico independentista en los momentos de consumación y consolidación del Estado de Cartagena. Esto a partir de las monedas acuñadas y el sello de la primera página de la Constitución. En el segundo aparte, se analiza la producción y elaboración de la emblemática local en el seno de los enfrentamientos entre republicanos y realistas durante 1811 y 1814. Teniendo presente que, la representación institucional a partir de la imagen indígena un fue un elemento de disputa. Todo lo anterior, se desarrolla a partir de la consulta de documentos constitucionales, filatélicos e imágenes de las alegorías, en su mayoría grabados y dibujos, que reposan en libros y mapas.

Palabras clave: Alegoría, América, Cartagena de Indias, iconografía, independencia, emblemas.

\begin{abstract}
The inhabitants of the Spanish colonies in the process of emancipation and conformation of the first republics constantly redesigned the allegory of America both in its iconographic representation and in its concept. Therefore, this text proposes to study the use of this allegory by the Junta Patriótica (Patriotic Assembly) to organize, represent and legitimize an independent administrative system in the Province of Cartagena between 1805 and 1814. In the first part, we explore the use of iconographic elements as part of the independence symbolic apparatus in the moments of consummation and consolidation of the State of Cartagena. This is based on the minted coins and the seal of the first page of the Constitution. In the second part, the production and elaboration of the local emblematic in the midst of the confrontations between republicans and royalists during 1811 and 1814 is analyzed. Bearing in mind that the institutional representation based on the indigenous image

\footnotetext{
${ }^{1}$ Historiadora, Estudiante del Doctorado en Historia, Universidad Nacional de San Martín, Argentina. Candidata a Magister en Historia Contemporánea Universidad Nacional de Sarmiento, Argentina. Especialista en Museos, transmisión cultural y
} manejo de colecciones, Universidad de Buenos Aires, Argentina.
\end{abstract}


was an element of dispute. All of the aforementioned is developed from the consultation of constitutional and philatelic documents and images of allegories, mostly engravings and drawings, which are found in books and maps.

Keywords: Allegory, America, Cartagena de Indias, iconography, independence, emblems.

\section{RESUMEM}

Os habitantes das colônias espanholas em processo de emancipação e formação das primeiras repúblicas redesenharam constantemente a alegoria da América, tanto em sua representação iconográfica quanto em seu conceito. Portanto, este texto se propõe a estudar o uso deste pelo Conselho Patriótico para organizar, representar e legitimar um sistema administrativo independente na Província de Cartagena entre 1805 e 1814. Na primeira seção, é explorado o uso dos elementos símbolos iconográficos como parte do aparato de independência simbólica nos momentos de consumação e consolidação do Estado de Cartagena. Isso a partir das moedas cunhadas e do selo da primeira página da Constituição. Na segunda seção, analisase a produção e elaboração da emblemática local no seio dos confrontos entre republicanos e monarquistas durante 1811 e 1814. Tendo presente que a representação institucional a partir da imagem indígena foi um elemento de disputa. Todo o anterior, é desenvolvido a partir da consulta dos documentos constitucionais, filatélicos e das imagens das alegorias, na sua maioria gravuras e desenhos, que se encontram em livros e mapas.

Palavras-chave: Alegoria, América, Cartagena de Indias, iconografia, independência, emblemas.

\section{Introducción}

En las primeras décadas del siglo XIX, la independencia para unos sectores del Virreinato de la Nueva Granada todavía no se planteaba como una cuestión de soberanía nacional, sino como un problema de independencia política. En este escenario se modificaron y ampliaron vocabularios y estrategias visuales para la representación del proyecto independentista criollo local y regional ${ }^{2}$. Estas en defensa de una nación libre se concentraron en deslegitimar el gobierno español desde el pasado violento en América. Para la instrumentalización de atributos, virtudes e ideas de libertad se apoyaron en la iconografía femenina asociada a la alegoría de América del siglo XVI (Acevedo, 2001; König, 1994). En esta línea, planteamos que, en la Provincia de Cartagena la adopción y resignificación de la Alegoría de America por parte de los patriotas buscaba organizar, representar y legitimar un sistema administrativo independiente. Por lo cual, este trabajo se preocupa por aproximarse al uso de la iconografía en los momentos de la consumación y consolidación de la Independencia del Estado de Cartagena. Para esto

${ }^{2}$ Rafael Acevedo, "La historia "trágica" de la conquista en los libros y los impresos de los hombres de letras en las provincias independientes de la Nueva Granada, 1811-1821”, en Araucaria, v.19, n.28, 2017, pp. 419-444. 
haremos énfasis en los elementos iconográficos empleados por la Junta Patriótica en la primera página de la Constitución del Estado de Cartagena de Indias, sancionada en 14 de junio del año de 1812 y las monedas acuñadas por el estado de Cartagena. Teniendo presente que, estos símbolos fueron creados, dotados de sentido y desplegados en un contexto político como expresión de una ideología y de un momento histórico preciso (Majluf, 2006: 203).

\section{Alegoría de América: sello y moneda del Estado de Cartagena}

La alegoría es la figura de la retórica que permite representar ideas incorporando personajes y figuras codificadas desde diferentes atributos. De acuerdo con un número importante de investigaciones en las que se analizan las alegorías de América, estas muestran elementos procedentes de la tradición novohispana desde el siglo XVI que asignaba atributos para significar ideas de América ${ }^{3}$. La mujer que representaba América tuvo diversas posibilidades de representación. Cesare Ripa en su obra Iconología (1593) acompañada de xilograbados se refiriere a América como una mujer desnuda, de bello cuerpo, con cabellos amplios, provista de un arco, una flecha, una bolsa o carcaj.

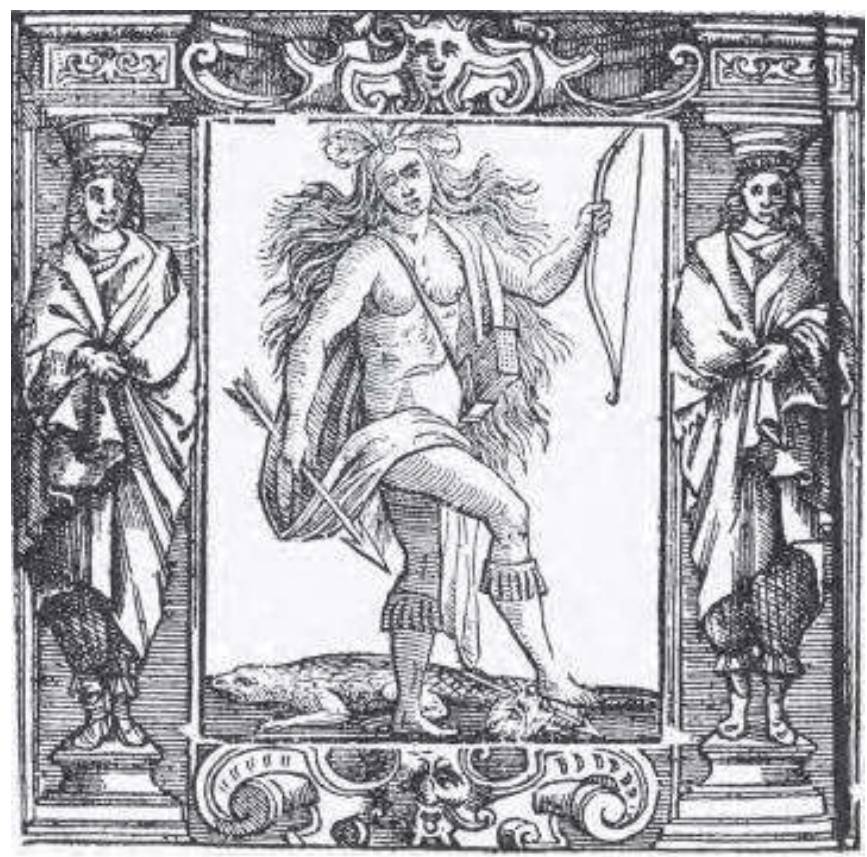

Ripa, Cesare. Alegoría de América. Iconología. Tomo II, Edición de Siena, 1613 R. Rey, "Los indígenas europeos: la india de la libertad. Colección de Numismática”.

\footnotetext{
${ }^{3}$ Esther Acevedo, "Entre la Tradición Alegórica y la Narrativa Factual", en Los Pinceles de la Historia. De la Patria Criolla a la Nación Méxicana 1750-1860. México: Consejo Nacional para la Cultura y las Artes, 2001, pp. 114-151; Yobenj Chicangana-Bayona, "Las Culturas Políticas de la Independencia, sus memorias y sus legados: 200 años de ciudadanías". Bogotá: Universidad Nacional de Colombia, 2010; Rebeca Earle, "La iconografía de la independencia en Cartagena y la Nueva Granada". En Calvo, Haroldo y Adolfo Meisel (eds). Cartagena de Indias en la independencia. Cartagena: Banco de la República, 2011, pp. 561-598; Juan Ricardo Rey, "Los indígenas europeos: la india de la libertad. Colección de Numismática". Cuadernos de Curaduría $N^{o}$ 2. Bogotá: Museo Nacional de Colombia, 2005; Hans König, En el camino hacia la Nación. Nacionalismo en el proceso de formación del Estado y de la Nación de la Nueva Granada 1750 a 1856. Bogotá: Banco de la República, 1994.
} 
También, América aparecía montando un armadillo, vestida de plumas y portando arco, carcaj, flechas y hacha como puede apreciarse en los grabados de Marten de Vos y Adriaen Collaert en 1600. Estas alegorías buscaban representar una alteridad diferente a lo europeo, inferior, exótica y primitiva como eran consideradas América y África en ese momento.

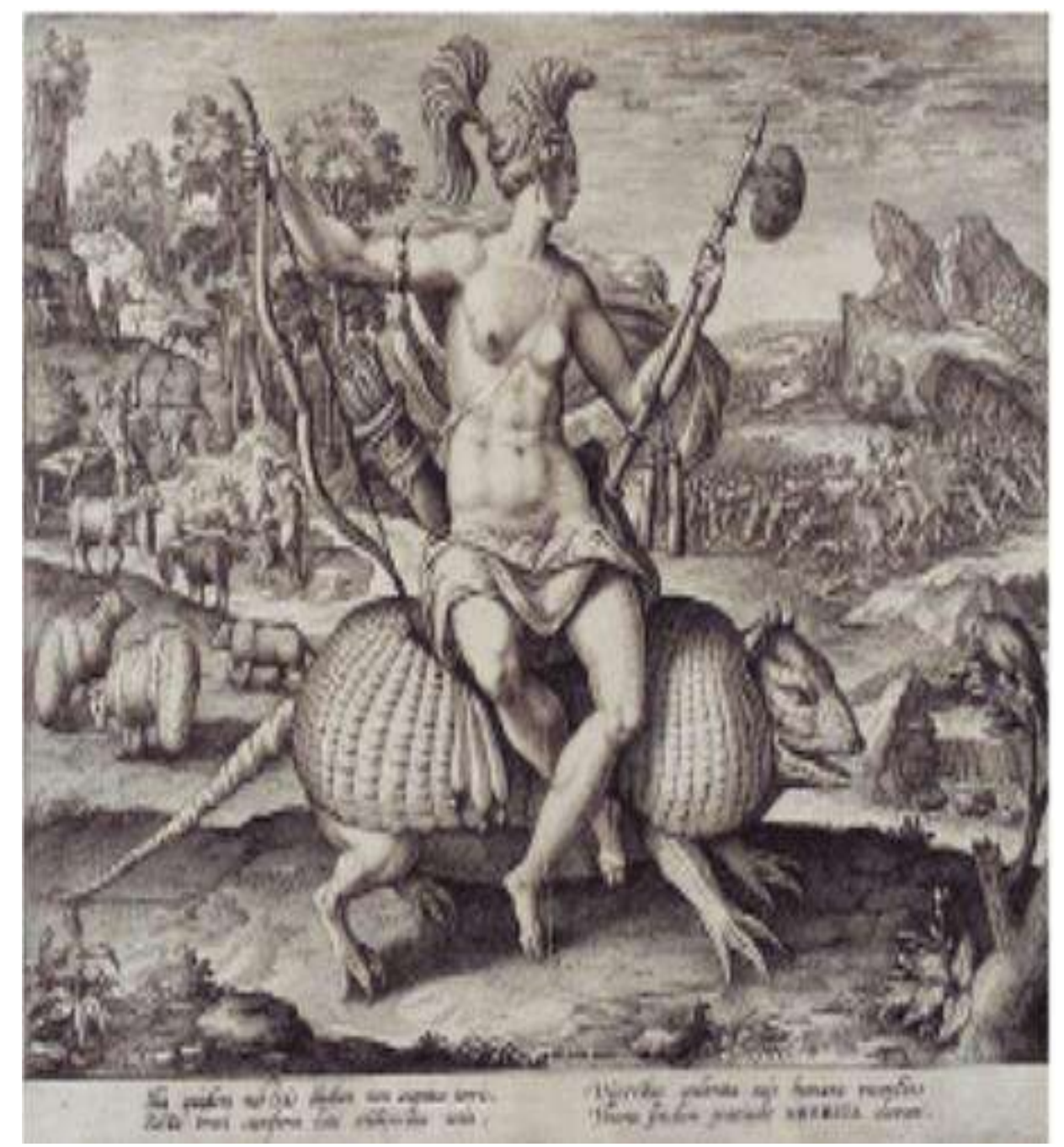

Marten de Vos y Adriaen Collaert. Las alegorías de los continentes, Amsterdam. 1600. Superior: América Y. Chicangana-Bayona, "Las Culturas Políticas de la Independencia".

En el contexto neogranadino, Marta Fajardo presenta una ilustración decorativa en la página principal de un manuscrito que describe las honras y exequias realizadas en Santafé en homenaje al Rey don Luís Fernando fechado el 12 de junio de $1726^{4}$. Este manuscrito es presidido por las alegorías de América a la izquierda de túnica, coronada con un penacho de plumas, flechas, arco y un loro en la mano derecha; y otra mujer de túnica, a la derecha que representa a Santafé, con una granada en la mano izquierda y a sus pies un águila.

${ }^{4}$ Marta Fajardo, “Arte y Poder. Las Honras Fúnebres del Rey Luis Fernando, el Primer Borbón Madrileño, en Santa Fé de Bogotá en el año de 1725”. XIV Congreso Colombiano de Historia, Tunja, 2008, p. 6. 


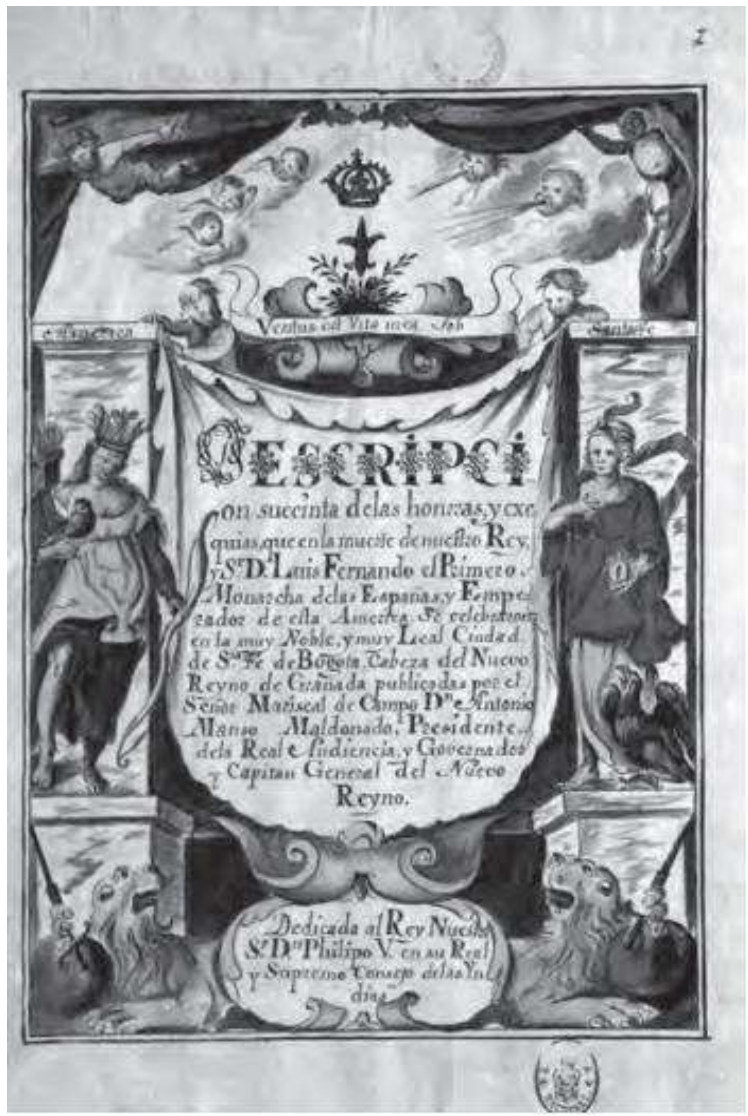

Descripción succinta de las honras. Anónimo. Acuarela sobre papel. Biblioteca Nacional de Madrid, sección manuscritos. Junio 13 de 1726. M. Fajardo,“Arte y Poder”, p. 5.

Estas alegorías están acompañadas de un texto que pretende demostrar de luto por la muerte del rey Luís Fernando e informar y destacar al nuevo Rey Felipe V. Y se articulan como representaciones de los territorios unidos por dichos episodios en la Real Audiencia.

Acevedo E. plantea que en el siglo XIX, las alegorías se adaptaron a las exigencias representativas. En el proceso de emancipación y la conformación de las primeras repúblicas, fueron resignificadas por los habitantes de las colonias españolas tanto en su representación iconográfica como en su concepto $^{5}$. Ricardo Rey anota que esto la convirtió en un símbolo de libertad, la patria y las identidades territoriales. Las indicaciones de lugar como paisajes costeros, cerros y frutos americanos se convirtieron en un identificador central para reencontrarse con las virtudes americanas. Dejando de lado los efectos negativos que teorías coloniales sobre el clima y la geografía desarrollaron desde las ciencias naturales ${ }^{6}$. En este sentido, Natalia Majluf propone que los criollos americanos ensayaron el surgimiento de un discurso patriótico basado en la celebración de la naturaleza local ${ }^{7}$. En la

\footnotetext{
${ }^{5}$ E. Acevedo, "Entre la Tradición Alegórica y la Narrativa Factual”, p. 115.

${ }^{6}$ R. Rey, "Los indígenas europeos: la india de la libertad. Colección de Numismática".

${ }^{7}$ Natalia Majluf, "Los fabricantes de emblemas. Los símbolos nacionales en la transición republicana. Perú, 1820-1825". En Ramón Mujica (ed.), Visión y símbolos. Del virreinato criollo a la república peruana. Lima: Banco de Crédito del Perú, 2006, p. 231.
} 
Nueva Granada, bajo el estímulo de la célebre Expedición Botánica que lideró José Celestino Mutis el pensamiento científico de la época se convirtió en un terreno de exploraciones que se interceptaban la ubicación geográfica, el pasado antiguo, la naturaleza e incluso la población ${ }^{8}$.

En la Provincia de Cartagena encontramos la disposición de la alegoría dentro de la cartografía. Esta se dispone al borde de un mapa topográfico, y se presenta como la mujer semidesnuda en medio de una fauna y flora americana como las palmas, el caimán gigante, el felino y loro, entre otros.

Este mapa topográfico corresponde a la renovación de los límites provinciales, la costa y el curso del Río Magdalena en 1805. Diseñado por el ingeniero militar Manuel de Anguiano bajo la plumilla de Antonio Caballero, hijo de Pablo Caballero Pimientel, pardo perteneciente a las milicias disciplinadas de Cartagena de Indias ${ }^{9}$. En este se exalta esa riqueza natural como parte de los conflictos de identidad y legitimidad que se recrudecerán con la búsqueda de la independencia política (Constitución política, junio 14 de 1812: 488). Representando ese camino a la "patria física y moral", la base sobre la cual se erigía luego la patria política, el pacto de asociación que reunía en torno a un orden superior la diversidad de los grupos que integraban la nación ${ }^{10}$.

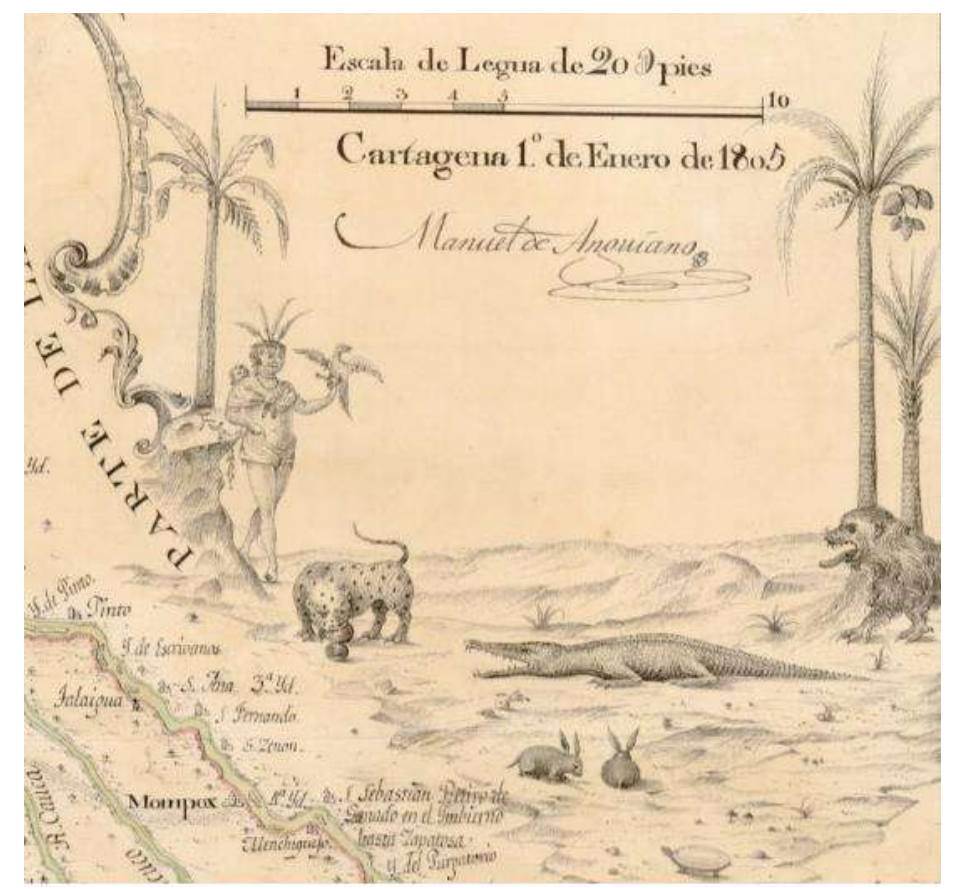

Título:Mapa Topografico de la Provincia de Cartagena de las Yndias en el Nuevo Reyno de Granada de la America Septentrional. Cartagena $1^{\circ}$ de Enero de 1805, Archivo Cartográfico de Estudios Geográficos del Centro Geográfico del Ejército - Colección: PCGE - Ubicación: AR - Signatura: Ar.J-T.7-C.1-27

\footnotetext{
${ }^{8}$ María T. Ripoll, "El Argos Americano: crónica de una desilusión”. En Calvo, Haroldo y Adolfo Meisel (eds). Cartagena de Indias en la independencia. Cartagena: Banco de la República, 2011, p. 531.

${ }^{9}$ Sergio Paolo Solano. "Artesanos, bellas artes, raza y política en Cartagena de Indias (Nuevo Reino de Granada) a finales de la colonia". Alcides Beretta (Coord.). Inmigración europea, artesanado y orígenes de la industria en América Latina. Uruguay: Universidad de la República, 2016, p. 114.

${ }^{10}$ N. Majluf, "Los fabricantes de emblemas", p. 237.
} 
Cartagena fue una provincia que se caracterizó por recibir durante la corona situados, tanto de Quito como del resto del Virreinato. Entre 1761 y 1800 representó el 43,1\% de los ingresos fiscales de las provincias caribeñas, le seguían en importancia los ingresos de los estancos de tabaco y aguardiente. Sergio Paolo Solano identifica que la negación por parte de las cortes de Cádiz a conceder el derecho de ciudadanía para todos los habitantes del imperio, extremaron y llevaron a estos sectores a identificar el anhelo de igualdad como algo solo posible bajo la forma republicana de gobierno. Entre 1808 a 1810, la crítica situación económica, el cierre de los frentes de trabajos y los enfrentamientos entre sectores de las esferas del poder, colocaron en el foco del descontento al gobernador Francisco Montes ${ }^{11}$. Los informes del Consulado de Comercio de Cartagena al virrey, entre 1800 y 1808, revelan la existencia de un consenso mutuo entre los comerciantes sobre los errores de la política mercantil de la corona en sus colonias ${ }^{12}$. Los atrasos en los pagos, recortes presupuestales, el alto costo de vida y la crisis política abierta desde 1808, habían creado una situación propicia para que los trabajadores concentrados se movilizaran. Meisel analiza que en 1810 Cartagena recibió el situado más bajo desde 1798, 212.500 pesos de plata, solo un 44,2\% del que se obtuvo en $1809^{13}$. Esa reducción, durante la llamada primera república (1811-1815) trajo consigo una aguda crisis fiscal ${ }^{14}$. los egresos aumentaban mientras los ingresos seguían en disminución por los gastos de la guerra con Santa Marta.

El comportamiento político de comerciantes, economistas y artesanos entre otros sectores se fue modificando paulatinamente. La movilización y radicalización de las aspiraciones por el descontento se expresaron a través de la política ${ }^{15}$. En esta línea, se organizó la primera Junta Suprema de Gobierno el 22 de mayo de 1810, liderada por patricios cartageneros. Entre los que se encontraban José Maria Garcia de Toledo, José Munive y Mozo, Miguel Diaz Granado, Santiago Lecuna, Santiago Gonzalez, José María de Castillo, Manuel Demetrio de Vega, José Maria Benito Revollo, Esusebio María Canabal, José Antonio de Ayos, José María Real, Manuel Anguiano, José María Castillo y Rada, Francisco del Fierro, José Antonio Amador ${ }^{16}$. Sergio Paolo Solano plantea que el Alcalde ordinario García de Toledo buscó a los maestros artesanos más sobresalientes de Cartagena para plantearles un posible compromiso con la creación de una junta de gobierno entre ellos Pedro Romero, Pedro Medrano, Nicolás Delfín, Cecilio Rojas, Martín Villa, Ramón Viaña y Silvestre Paredes. Estos pardos se desempeñaban como

\footnotetext{
${ }^{11}$ S. P. Solano. "Artesanos, bellas artes, raza y política en Cartagena de Indias”, p. 114.

${ }^{12}$ M. T. Ripoll, "El Argos Americano: crónica de una desilusión”, p. 532.

13 Adolfo Meisel, "La crisis fiscal de Cartagena en la era de la independencia, 1808-1821". En La Corona en llamas: Conflictos económicos y sociales en las Independencias iberoamericanas, eds. José Serrano y Luís Jauregui, 2010 , Valencia: Universitat Jaume I. pp. 173-196.

${ }^{14}$ Sergio Paolo Solano, "Artesanos, jornaleros y formas concentradas de trabajo: el Apostadero de la Marina de Cartagena de Indias (Nuevo Reino de Granada) en el tránsito entre los siglos XVIII y XIX”. Theomai. 31, 1, $2015,87$.

${ }_{15}$ Alfonso Múnera, El fracaso de la nación. Bogotá, Banco de la República//El Áncora Eds., 1998; S. P. Solano. "Artesanos, jornaleros y formas concentradas de trabajo",

16 "Acta del Cabildo de Cartagena, en que consta el reconocimiento que han hecho varias autoridades de Mompox, de la nueva forma de Gobierno de la Provincia", junio 8 de 1810: 92. En: Corrales, Manuel E. 1883. Documento para la historia de la Provincia de Cartagena de Indias. Bogotá: Imprenta Medrano Rivas.
} 
trabajadores del apostadero de la Marina, obras de fortificaciones, pulperías y en la coordinación de las milicias en la ciudad ${ }^{17}$. Esto desembocó la independencia absoluta del 11 de noviembre de 1811.

La Junta Patriótica de Cartagena después de declarar su independencia absoluta el 11 de noviembre de 1811, se preocupó por reproducir representaciones de insignia. En esta línea, se retoma la alegoría de América con un carcaj, arco y flechas en el contexto republicano. emblema de libertad e independencia; continúa apareciendo como una mujer semidesnuda vestida de plumas (penacho y faldas) como se aprecia en la primera página de la Constitución del Estado de Cartagena de Indias, sancionada en 14 de junio del año de 1812. En este sello la figura femenina alimenta un ave con una granada que sostiene en su mano derecha; y en su mano izquierda cuelgan unas cadenas. El paisaje que le corresponde está compuesto por dos cerros con edificaciones el de la derecha ha sido identificado como el cerro de la $\mathrm{Popa}^{18}$.

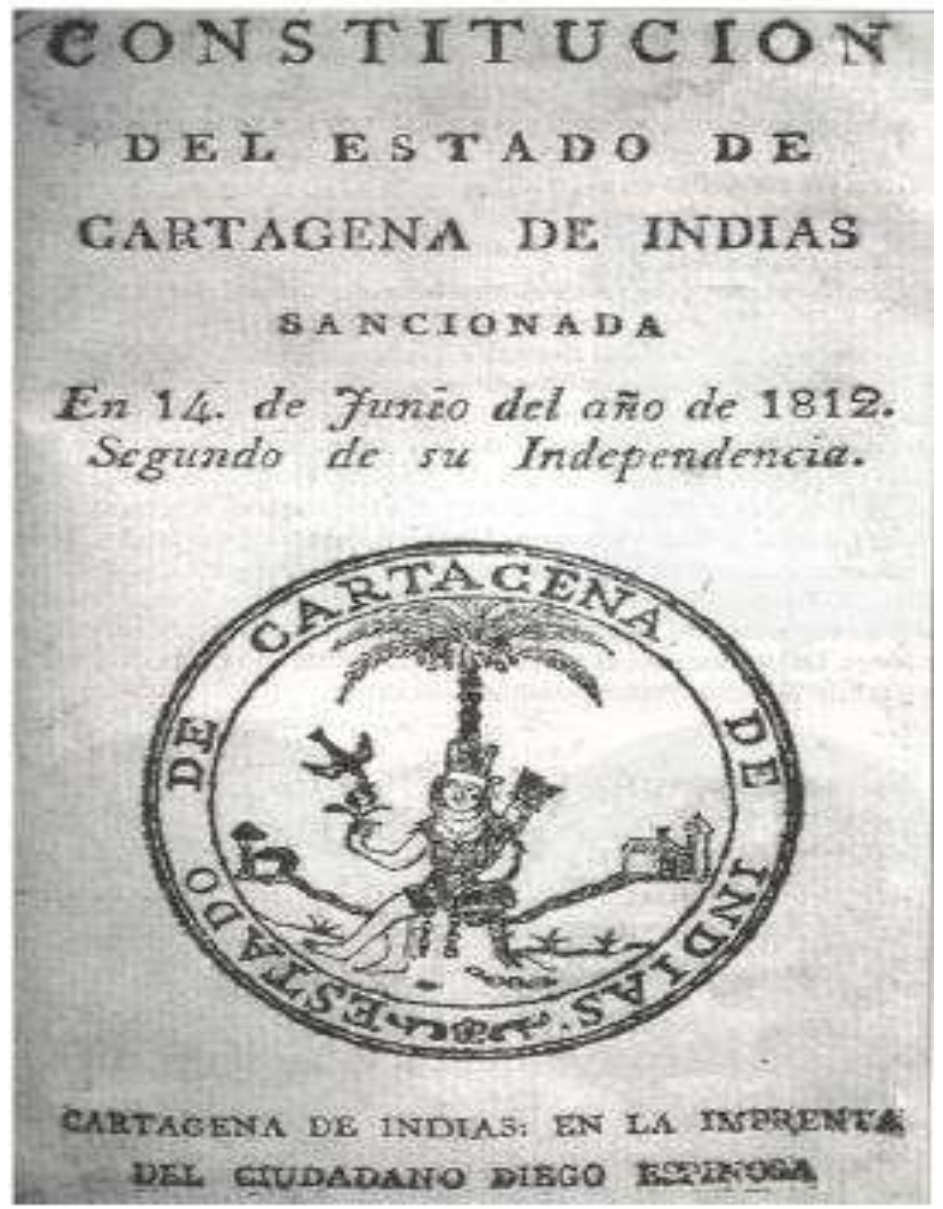

Constitución del estado de Cartagena de Indias. Fuente: Barriga del Diestro, F. (2002, Abril-Junio) Heráldica y silografía en la Independencia y en la República de Colombia. Boletín de historia y

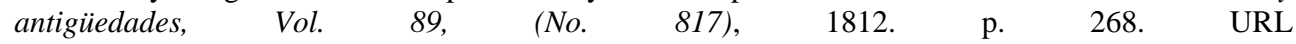
http://babel.banrepcultural.org/cdm/ref/collection/p17054coll10/id/3544

${ }^{17}$ S. P. Solano. "Artesanos, jornaleros y formas concentradas de trabajo", p. 100.

${ }^{18}$ R. Rey, "Los indígenas europeos: la india de la libertad. Colección de Numismática". 
La resignificación de la alegoría en el sello del acta de la declaración de Independencia a punta a la representación pública del cambio político, de ese pacto social que señalaba la fundación de un nuevo orden sociedad. En el reverso de las monedas acuñadas por el Estado de Cartagena se repite la silueta de la india de este sello en un fondo distinto, donde los cerros son sustituidos por palmeras. En el anverso tenían la inscripción Estado de Cartagena, la cifra $1 / 2$ y el año de acuñación. Tanto las monedas de medio real, como las de dos reales, se acuñaron en $1811,1812,1813$ y $1814^{19}$.

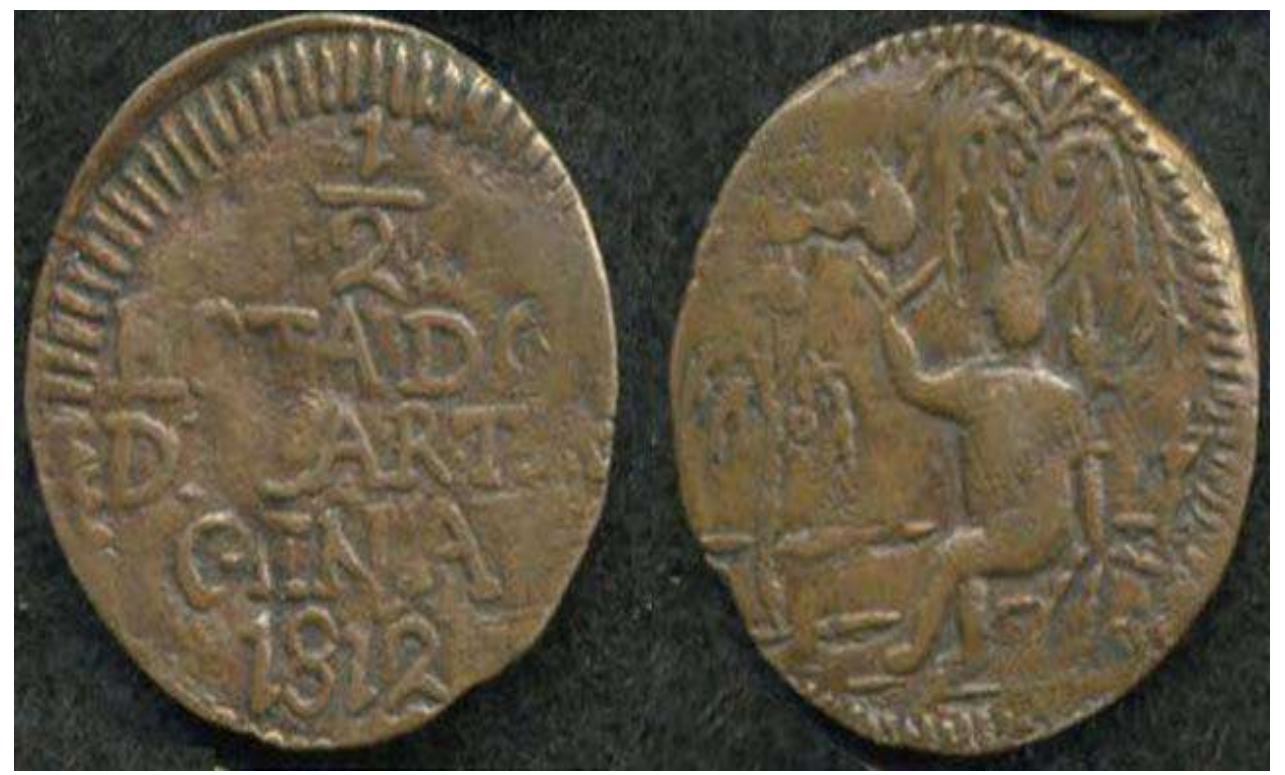

Anverso y reverso. Moneda de Cartagena de medio real. 1812. Fuente: Barriga del Diestro, F. (2002, Abril-Junio) Heráldica y silografía en la Independencia y en la República de Colombia. Boletín de historia y antigüedades, Vol. 89, (No. 817), p. 267. Restrepo Jorge, Monedas en Colombia 1808- 1886. Desde Fernando VII hasta Estados Unidos de Colombia. Editorial Colina. Medellín, 1989

El sello y la moneda del Estado de Cartagena surgieron para reproducción institucional. Estas representaciones circularon simultáneamente aludiendo a un "vehículo de recordación de la autoridad y un símbolo de soberanía"20. Los diseñadores de los símbolos independentistas avivaron signos de indios imaginarios recuperados de una visión de origen europeo. Lejos de señalar a los indígenas que habitaban en ese momento la Nueva Granada, el proyecto republicano se basaba en el pasado de las civilizaciones prehispánicas para deslegitimar la autoridad española. Esta metáfora se convirtió en emblema. Situaciones que continuaremos desplegando en el siguiente aparte.

La alegoría de América cobró un sentido protagónico, en su resignificación adquirió una independencia simbólica en la iconografía utilizada por los insurgentes para decorar las monedas, los escudos nacionales y las banderas. La identidad territorial en esta fue el marco en el cual, se reapropiaron

\footnotetext{
${ }^{19}$ Actualidad filatélica. "La moneda en la independencia: monedas y billetes del Estado Libre de Cartagena", julio 1 de 2017. URL: http://actualidadfilatelica.blogspot.com/2017/07/las-monedas-de-la-independencia-monedas.html Biblioteca Nacional de Colombia (en adelante BNC),

http://babel.banrepcultural.org/cdm/ref/collection/p17054coll10/id/3544

${ }^{20}$ N. Majluf, "Los fabricantes de emblemas", 227.
} 
discusiones de la naturaleza, dominación y legitimidad política por parte de los republicanos. En un llamado del Congreso en 1812 en Leiva, esto se registra:

Corred, pues, á inscribiros en la lista de los verdaderos amigos de nuesta causa, de los verdaderos americanos, de los hombres libres que no nacieron para vivir humillados bajo un yugo extranjero y de tantos amos, cuantos por haber nacido solo en el otro hemisferio se crean de una naturaleza y de un órden superior á vosotros. A vosotros, á quienes el Cielo ha prodigado a sus dones, enriqueciéndoos de todos los talentos y disposiciones necesarias para gobernaros y haceros felices á vosotros mismos ${ }^{21}$.

\section{La reapropiación de la imagen en medio de la lucha independentista}

En la creación del aparato simbólico independentista lo indígena se articuló como instrumento político y no como identidad política. Por lo cual, entre 1811 y 1814 esta iconografía en el sello y las monedas propuesta por la Junta Patriótica intentó organizar, representar y justificar un sistema administrativo y económico independiente. Su uso en la actividad jurídica, política y económica del Estado de Cartagena buscaba presentar la instauración de un régimen institucional frente a la dominación española.

Rebeca Earle propone que con la emancipación absoluta el sello del Estado de Cartagena abandonó el imaginario utilizado durante la colonia montañas, un arroyo y un barco - para reemplazarlo por una mujer indígena $^{22}$. Para acuñar las monedas se recurrió a las planchas de cobre que estaban almacenadas en los depósitos de la marina utilizadas en la protección de los cascos de las naves ${ }^{23}$. La circulación de las mismas se puede atribuir al servicio de los artesanos de la mano con la Junta patriótica, entre ellos, Pedro Romero quien poseía talleres de herreros, fundidores, armeros y carpinteros estaban encargados de la creación, mantenimiento y refacción de armamentos y sus aparejos ${ }^{24}$.

Además, detrás de la producción de monedas patriotas había un interés por cubrir el déficit financiero y conseguir recursos para financiar las guerras. La emisión de papel moneda quedó plasmada a nivel constitucional al erigir como obligatorio el cumplimiento de la Ley del 23 de marzo de 1812; sin embargo, esto no trajo consigo estabilidad financiera. Las monedas que se empezaron a acuñar, no tenían el valor intrínseco de las españolas, acuñadas en oro y plata, por lo cual la emisión no activo positivamente la economía. Por otro lado, la reproducción del elemento simbólico que estaba

\footnotetext{
21 "El Congreso. Reunido en Leiva se dirige a los pueblos". noviembre 2 de 1812. En: Manuel E. Corrales, 1883. Documento para la historia de la Provincia de Cartagena de Indias. Bogotá: Imprenta Medrano Rivas, 1886, p. 482.

${ }^{22}$ R. Earle, "La iconografía de la independencia en Cartagena y la Nueva Granada", p. 573.

${ }^{23}$ Actualidad filatélica. "La moneda en la independencia: monedas y billetes del Estado Libre de Cartagena"; Jorge Restrepo, .Monedas en Colombia 1808- 1886. Desde Fernando VII hasta Estados Unidos de Colombia. Medellín: Editorial Colina, 1989.

${ }^{24}$ S. P. Solano. “Artesanos, jornaleros y formas concentradas de trabajo”, p. 96.
} 
representado en la moneda permitía legitimar el cambio político. En esta línea, la acuñación y circulación de la moneda con el diseño de una alegoría de America se convirtió en un mensaje de cambio luego del 11 noviembre de $1811^{25}$. Rafael Acevedo dice que el tema de la conquista se constituía pues en uno de los referentes políticos y culturales, justo en una época caracterizada por cierto despertar y sentimiento de "patriotismo herido" 26.

En la Constitución sancionada el 14 de junio de 1812, conformada por 25 títulos y 127 artículos trae a colación la teoría del pacto social de la totalidad del pueblo ${ }^{27}$. Se habla de la separación "para siempre" de la Monarquía Española, de la dejación de "trescientos años de vejaciones, de miserias, de sufrimientos de todo género que acumuló sobre nuestro país la ferocidad de sus conquistadores y mandatarios españoles, cuya historia no podrá leer la posteridad sin admirarse de tan largo sufrimiento..."28.

La deslegitimación de la autoridad de los reyes de España en América está constantemente en cuestión haciendo llamamientos "¿Habeis olvidado vuestra suerte en 300 años?;Habeis visto que se conviertan en vuestro provecho los tesoros inmensos que han corrido de América para no volver jamás?... Apresuraos á depositar en el seno de la Patria parte de lo que ella misma os ha dado"29. Y sobre todo, tal como se manifestaba en el Catecismo de Sotomayor, con la explotación sufrida por "[...] Los indios que desgraciadamente eran repartidos, o vendidos como esclavos a los mismos conquistadores [...]". Juan Fernández de Sotomayor y Picón, siendo cura vicario de Mompox en 1811, fue uno de los partidarios más entusiastas de la causa liberal en Cartagena- en 1814 publicó su Catecismo-, diputado del Estado de Cartagena ante el Congreso General de la Unión ${ }^{30}$. Acevedo explica que la figura del indio se empleó para justificar el "fundamento legítimo" de la nueva patria independiente, patria que, al menos en el lenguaje político del Catecismo de Sotomayor y Picón, era definida como el "precioso derecho de existir libres de la tiranía"31.

En el discurso de "tres siglos de vejaciones" se consolidaron contradicciones durante la época de la independencia entre los republicanos y los realistas. El ataque realista al pasado precolombino se acompañaba a menudo de una abierta defensa de la conquista española y la colonización de las Américas ${ }^{32}$. Esta situación contradictoria se ve también en el acto de federación de las Provincias Unidas de la Nueva Granada, escrito en 1811 donde los indígenas eran a la vez legítimos propietarios y bárbaros. Earle resalta el caso de Caldas

\footnotetext{
${ }^{25}$ Carlos Delgado, Exposición. Financiación de la Independencia. Museo Casa de Moneda-Banco de la República. Noviembre 16 de 2011 a 31 de julio de 2013.

${ }^{26}$ R. Acevedo, "La historia "trágica" de la conquista en los libros y los impresos de los hombres de letras", p. 429.

27 "Apéndice. Constitución política del Estado de Cartagena de Indias", junio 14 de 1812: En: Manuel E.Corrales, Documento para la historia de la Provincia de Cartagena de Indias. Bogotá: Imprenta Medrano Rivas, 1883, p. 546.

${ }^{28}$ Apéndice. Constitución política del Estado de Cartagena de Indias".

29 "El Congreso. Reunido en Leiva se dirige a los pueblos". noviembre 2 de 1812. En: Manuel E. Corrales, Documento para la historia de la Provincia de Cartagena de Indias. Bogotá: Imprenta Medrano Rivas, 1883.

${ }^{30}$ Juan Fernández de Sotomayor y Picón, Catecismo o instrucción popular. Bogotá: Editorial Kelly, 1976, p. 21.

${ }^{31}$ R. Acevedo, "La historia "trágica" de la conquista en los libros y los impresos de los hombres de letras", p. 428.

${ }^{32}$ H. König, En el camino hacia la Nación, pp. 225-226.
} 
describió a los indígenas colombianos como bárbaros perezosos en 1812, aunque hacía un año había echado la culpa por su degradación no a su pereza sino al mal gobierno español ${ }^{33}$.

Estas distintas posiciones dentro del proceso independentista permiten identificar que la legitimidad política, pone en fuego un discurso que está en constante enfrentamiento. Y este trae consigo una identificación desde la materialidad. Los indígenas fueron los principales actores en la producción y elaboración de la emblemática local. La presencia de indias entre los elementos iconográficos empleados manifiesta una serie de la contradicción inherente a la percepción de los indígenas durante la Primera República debido a los enfrentamientos entre los republicanos y realistas. Por lo cual, una de las tareas patrióticas consistió en dotar de sentido y circular dicha representación.

\section{Consideraciones finales}

La alegoría de América acogida por los movimientos independentistas fue resignificada en el seno de los conflictos de interés político para convertir en una representación de su legitimidad administrativa. Esta se transforma tal como propone Rey en alegoría de la libertad dentro de proceso de apropiación y transformación ${ }^{34}$. En este sentido, en la lucha independentista dentro del Estado de Cartagena la composición de la figura del indígena termino ocupando un lugar privilegiado. En esta línea, podemos pensar que las monedas y el sello del Estado de Cartagena se convirtieron representaciones del simbolismo insurgente tras la necesidad que había de legitimar esos símbolos en un proceso político. La actividad jurídica, política y económica del Estado de Cartagena buscaba presentar la instauración de un régimen institucional consolidado. En el cual era necesario relegar ese pasado español, como una operación selectiva de legitimación.

\section{Bibliografía}

"Acta del Cabildo de Cartagena, en que consta el reconocimiento que han hecho varias autoridades de Mompox, de la nueva forma de Gobierno de la Provincia", junio 8 de 1810: 92. En: Corrales, Manuel E. 1883. Documento para la historia de la Provincia de Cartagena de Indias. Bogotá: Imprenta Medrano Rivas.

"Apéndice. Constitución política del Estado de Cartagena de Indias", junio 14 de 1812: 546. En: Corrales, Manuel E. 1883. Documento para la historia de la Provincia de Cartagena de Indias. Bogotá: Imprenta Medrano Rivas.

"Apuntamientos para escribir una ojeada sobre la historia de la transformación política de la Provincia de Cartagena": 124. En: Corrales, Manuel E. 1883.

\footnotetext{
${ }^{33}$ Rebeca Earle, The return of the native: Indians and myth-making in Spanish America, 1810-1930. Durham Duke Uniersity, 2007, p. 14.

${ }^{34}$ R. Rey, "Los indígenas europeos: la india de la libertad. Colección de Numismática".
} 
Documento para la historia de la Provincia de Cartagena de Indias. Bogotá: Imprenta Medrano Rivas.

"El Congreso. Reunido en Leiva se dirige a los pueblos". noviembre 2 de 1812. En: Manuel E. Corrales, 1883. Documento para la historia de la Provincia de Cartagena de Indias. Bogotá: Imprenta Medrano Rivas.

Acevedo, Esther, "Entre la Tradición Alegórica y la Narrativa Factual", en Los Pinceles de la Historia. De la Patria Criolla a la Nación Méxicana 17501860 (pp. 114-151). México: Consejo Nacional para la Cultura y las Artes, 2001.

Acevedo, Rafael, "La historia "trágica" de la conquista en los libros y los impresos de los hombres de letras en las provincias independientes de la Nueva Granada, 1811-1821”, en Araucaria, v.19, n.28, 2017, pp. 419-444.

Actualidad filatélica. "La moneda en la independencia: monedas y billetes del Estado Libre de Cartagena", julio 1 de $2017 . \quad$ URL: http://actualidadfilatelica.blogspot.com/2017/07/las-monedas-de-laindependencia-monedas.html

Barriga del Diestro, F. "Heráldica y silografía en la Independencia y en la República de Colombia”. Boletín de Historia y Antigüedades, 89, 817, 2002.

Chicangana-Bayona, Yobenj, "Las Culturas Políticas de la Independencia, sus memorias y sus legados: 200 años de ciudadanías". Bogotá: Universidad Nacional de Colombia, 2010.

Chicangana-Bayona, Yobenj, "La India de la libertad: de las alegorías de América a las alegorías de la patria", en Argos, v.27 n.53, 2010. URL: http://ve.scielo.org/scielo.php?pid=S025416372010000200007\&script=sci_artte $\underline{\mathrm{xt}}$

Chicangana-Bayona, Yobenj, La independencia en el arte y el arte en la independencia. Bogotá: Ministerio de Educación Nacional, 2009.

Fernández de Sotomayor y Picón, Juan, Catecismo o instrucción popular. Bogotá: Editorial Kelly, 1976.

Delgado Carlos, Exposición. Financiación de la Independencia. Museo Casa de Moneda-Banco de la República. Noviembre 16 de 2011 a 31 de julio de 2013.

Earle, Rebeca, The return of the native: Indians and myth-making in Spanish America, 1810-1930. Durham Duke Uniersity, 2007.

Earle, Rebeca, "La iconografía de la independencia en Cartagena y la Nueva Granada". En Calvo, Haroldo y Adolfo Meisel (eds). Cartagena de Indias en la independencia. (561-598). Cartagena: Banco de la República, 2011.

Fajardo, Marta, "Arte y Poder. Las Honras Fúnebres del Rey Luis Fernando, el Primer Borbón Madrileño, en Santa Fé de Bogotá en el año de 1725". XIV Congreso Colombiano de Historia, Tunja, 2008. 
González, Beatriz, Manual de arte del siglo XIX en Colombia. URL: https://books.google.com.ar/books?id=b8JdDwAAQBAJ\&pg=PA130\&lpg=PA1 $\underline{30 \& \mathrm{dq}=\text { acuarela }+ \text { cartagena }+ \text { de }+ \text { indias }+ \text { siglo }+x i x \& \text { source }=\mathrm{bl} \& \text { ots }=04 \text { PgnLVS3 }}$ 8\&sig=ACfU3U0hD-DyKxN4AzWHdJ151_qi5JNK0Q\&hl=es419\&sa=X\&ved=2ahUKEwjcorb1LbpAhWJHbkGHXtqDL0Q6AEwC3oECAg QAQ\#v=onepage \&q=cartagena $\% 20 \& \mathrm{f}=$ false

König, Hans, En el camino hacia la Nación. Nacionalismo en el proceso de formación del Estado y de la Nación de la Nueva Granada 1750 a 1856. Bogotá: Banco de la República, 1994.

Majluf, Natalia, "Los fabricantes de emblemas. Los símbolos nacionales en la transición republicana. Perú, 1820-1825”. En Ramón Mujica, ed., Visión y símbolos. Del virreinato criollo a la república peruana, pp. 203-241. Lima: Banco de Crédito del Perú, 2006

Meisel, Adolfo, "La crisis fiscal de Cartagena en la era de la independencia, 18081821". En La Corona en llamas: Conflictos económicos y sociales en las Independencias iberoamericanas, eds. José Serrano y Luís Jauregui, 2010, Valencia: Universitat Jaume I. pp. 173-196.

Morales, Daniela, Álvarez, Alihuen y Jorgelina, Araceli, "El discurso de lo indígena en la creación de la identidad nacional. Una mirada hacia la construcción de nación, los discursos en disputa y el imaginario social en las imágenes de los grupos independentistas de América a principios del siglo XIX". URL: http://sedici.unlp.edu.ar/bitstream/handle/10915/66638/Documento_completo.pd f-PDFA.pdf?sequence $=1 \&$ isAllowed $=y$

Múnera, Alfonso, El fracaso de la nación. Bogotá, Banco de la República//El Áncora Eds., 1998

Restrepo, Jorge, Monedas en Colombia 1808- 1886. Desde Fernando VII hasta Estados Unidos de Colombia. Medellín: Editorial Colina, 1989.

Rey, Juan Ricardo, "Los indígenas europeos: la india de la libertad. Colección de Numismática". Cuadernos de Curaduría $N^{o}$ 2. Bogotá: Museo Nacional de Colombia, 2005, pp. 11.

Ripoll, María T., "El Argos Americano: crónica de una desilusión”. En Calvo, Haroldo y Adolfo Meisel(Eds). Cartagena de Indias en la independencia. (529560). Cartagena: Banco de la República, 2011.

Solano, Sergio Paolo. “Artesanos, bellas artes, raza y política en Cartagena de Indias (Nuevo Reino de Granada) a finales de la colonia". Alcides Beretta (Coord.). Inmigración europea, artesanado y orígenes de la industria en América Latina. Uruguay: Universidad de la República, 2016: 113-142

Solano, Sergio Paolo. "Artesanos, jornaleros y formas concentradas de trabajo: el Apostadero de la Marina de Cartagena de Indias (Nuevo Reino de Granada) en el tránsito entre los siglos XVIII y XIX”. Theomai. 31(1).2015: 79-105. 